\title{
A case report of fulminant type 1 diabetes mellitus associated with drug-induced hypersensitivity syndrome in an elderly patient with coxsackie B4 virus infection and human leukocyte antigen-A24 haplotype
}

\author{
Ayumu Takeno ${ }^{1)}$, Ippei Kanazawa' ${ }^{1)}$, Miwa Morita ${ }^{1)}$, Kai Takedani ${ }^{1)}$, Hitomi Miyake ${ }^{1)}$, \\ Masahiro Yamamoto ${ }^{1)}$, Kyoko Nogami ${ }^{2)}$, Sakae Kaneko ${ }^{2)}$ and Toshitsugu Sugimoto ${ }^{1)}$ \\ 1) Internal Medicine 1, Shimane University Faculty of Medicine, 89-1, Enya-cho, Izumo, Shimane 693-8501, Japan \\ 2) Department of Dermatology, Shimane University Faculty of Medicine, 89-1, Enya-cho, Izumo, Shimane 693-8501, Japan
}

\begin{abstract}
Drug-induced hypersensitivity syndrome (DIHS) is a severe systemic adverse drug reaction. Previous studies showed that DIHS is associated with the onset of fulminant type 1 diabetes mellitus (FT1D). Although genetic background and abnormalities in immune response or viral infection are considered to be associated with pathogenesis of FT1D, it remains unclear whether virus infection and specific human leukocyte antigen (HLA) typing are involved in DIHS-associated FT1D. Here, we report a case of a 78-year-old female patient with FT1D after DIHS treatment. She was diagnosed as DIHS caused by carbamazepine, and treatment with predonisolone was initiated. After 46 days from the occurrence of DIHS, she was admitted to our hospital because of type 1 diabetes mellitus and diabetic ketoacidosis. Although her Hemoglobin A1c (HbA1c) was elevated by predonisolone treatment (HbA1c: 9.2\%), we diagnosed her as fulminant type 1 diabetes mellitus considering the abrupt onset of the ketoacidosis. Her general condition was improved by treatment with fluid infusion and insulin administration. During her clinical course, the infection of coxsackie B4 virus was observed. In addition, the examination of HLA typing showed HLA-A24 haplotype. These findings suggest that the coxsackie B4 virus infection may be involved in the pathogenesis of DIHS-induced FT1D, and that HLA-A24 haplotype might relate to DIHS-associated FT1D.
\end{abstract}

Key words: Fulminant type 1 diabetes mellitus, Drug-induced hypersensitivity syndrome, Coxsackie virus B4

FULMINANT TYPE 1 DIABETES MELLITUS (FT1D) is a subtype of type 1 diabetes mellitus characterized by extremely rapid progression of hyperglycemia and diabetic ketoacidosis (DKA) due to almost complete pancreatic beta-cell destruction $[1,2]$. Because FT1D often causes poor prognosis, we have to pay special attention to the development of FT1D in clinical settings. Drug-induced hypersensitivity syndrome (DIHS) is a severe systemic adverse drug reaction characterized by rash, fever, leukocytosis, eosinophilia and liver injury [3, 4]. Reactivation of human herpes virus 6 (HHV-6) is one

Submitted Jun. 8, 2017; Accepted Sep. 4, 2017 as EJ17-0249

Released online in J-STAGE as advance publication Sep. 29, 2017

Correspondence to: Ippei Kanazawa, Internal Medicine 1, Shimane

University Faculty of Medicine, 89-1, Enya-cho, Izumo, Shimane, 693-8501, Japan

E-mail: ippei.k@med.shimane-u.ac.jp of specific characteristics of DIHS [3]. Recently, it is reported that FT1D sometimes occurs after DIHS treatment $[4,5]$. Indeed, Onuma et al. previously reported that the clinical characteristics of FT1D with DIHS were similar to those without DIHS, but the frequency was much higher than that in the general population $(0.54 \%$ vs. $0.01 \%$ ) [4]. Because the mechanism of DIHSassociated FT1D still remains unclear, the investigation of clinical characteristics including genetic background and serological testing for viral infection are necessary to clarify this issue.

\section{Case Report}

A 78-year-old female patient visited a clinic for her blepharospasm and was prescribed carbamazepine. One month later, maculopapular rash occurred in her face, 
trunk, and extremities. She was admitted to the department of dermatology in our hospital. Although she did not have high grade fever $\left(37.4^{\circ} \mathrm{C}\right)$, lymphadenopathy, eosinophilia or lymphocytosis, she met a possible case of DIHS by European Registry of Severe Cutaneous Adverse Reactions (RegiSCAR) [6] based on maculopapular rash after medication of carbamazepine, liver dysfunction (aspartate aminotransferase $39 \mathrm{U} / \mathrm{L}$; normal range $13-30 \mathrm{U} / \mathrm{L}$, alanine aminotransferase $31 \mathrm{U} / \mathrm{L}$; normal range 7-23 U/L) and exclusion of other alternative diseases. Because DIHS caused by carbamazepine was suspected, carbamazepine was discontinued and administration of predonisolone (PSL) $40 \mathrm{mg} /$ day was initiated. Her hemoglobin Alc (HbA1c) level was $6.2 \%$ on the admission. Thereafter, her rash was improved; thus the dose of PSL was gradually tapered. In the clinical course, the titer of anti-HHV-6 IgG was increased to 40:640 (16-fold increase) and the drug-induced lymphocyte stimulation test (DLST) for carbamazepine was positive; thus carbamazepine-induced DIHS was confirmed. Her plasma glucose levels at evening and night were increased up to 200 to $250 \mathrm{mg} / \mathrm{dL}$ after the PSL administration. Because PSL dose was decreased to $10 \mathrm{mg}$ /day, she was discharged without any anti-diabetic drugs.

After 46 days from the occurrence of DIHS, she was taken to our hospital because of unconsciousness. On physical examination, Glasgow coma scale was E3V4M6. Her body temperature was $35.6^{\circ} \mathrm{C}$ and other vital signs were fortunately within normal range. Her skin turgor was decreased. She did not have abdominal pain. Laboratory examination showed hyperglycemia (plasma glucose: $649 \mathrm{mg} / \mathrm{dL}$ and $\mathrm{HbA} 1 \mathrm{c} 9.2 \%$ ) and metabolic acidosis (pH: 7.338, $\mathrm{HCO}_{3}: 13.7 \mathrm{mmol} / \mathrm{L}$ ), and urine ketone was 4 plus; therefore, we diagnosed DKA. We promptly started fluid infusion and insulin administration. Although all of anti-islet antibodies (antiglutamic acid decarboxylase antibody, anti-insulinomaassociated antigen- 2 antibody, insulin autoantibody, antizinc transporter 8 antibody, and islet cell cytoplasmic autoantibody) were negative, her insulin secretory function was extremely inhibited; urine C-peptide $1.8 \mu \mathrm{g} / \mathrm{day}$ at fifth hospital day and $1.2 \mu \mathrm{g} /$ day at 28th hospital day (normal range; 24-97 $\mu \mathrm{g} / \mathrm{day}$ ), and no response for glucagon loading test (serum C-peptide $<0.2 \mathrm{ng} / \mathrm{mL}$ at basal and $0.2 \mathrm{ng} / \mathrm{mL}$ at $6 \mathrm{~min}$ ). Serum amylase was increased $(178 \mathrm{U} / \mathrm{L}$; normal range 44 to $132 \mathrm{U} / \mathrm{L})$. Although her $\mathrm{HbA} 1 \mathrm{c}$ was elevated by PSL treatment for DIHS, we diagnosed as FT1D according to its criteria [7].

\section{Serological Testing for Virus Infections}

To investigate the association between viral infection and FT1D, we performed serological testing for several viruses such as, herpes viruses, parainfluenza virus B1-3, coxsackie virus A2-7, 9, 10, 16 and B1-6, at 11 and 54 days after the admission (Table 1). Coxsackie B4 virus antibody titer was significantly elevated from $1:<4$ to 1:64 (16-fold increase), whereas all other antibodies were not altered.

\section{HLA Typing}

Furthermore, we examined her human leukocyte antigen (HLA) typing. The HLA haplotyping was performed with HLA typing kits of Scisco Genetics Inc (Seattle, WA). Exon 1 to 7 of HLA-A, B and C, as well as exon 1 to 4 of HLA-DR, DQ and DP were examined by next generation sequencing with MiSeq (Illumina, San Diego, CA). The results were analyzed by using a software GeMS HLA (Scisco Genetics Inc., Seattle, WA). HLA-A*11:01/24:02, B*40:02/67:01, DRB1*15:01/-, DQA $1 * 01: 02 /-$, and DQB $1 * 06: 02 /-$ were identified.

\section{Discussion}

We described a case of elder female patient who had FT1D associated with carbamazepine-induced DIHS. The serological testing showed that the antibody titer of coxsackie B4 virus, but not others, was significantly elevated in the clinical course, suggesting that infection of coxsackie B4 virus may be involved in the pathogenesis of FT1D. Although the pathogenesis of FT1D remains to be elucidated, it is suggested that viral infection plays important roles in its onset [8]. Akatsuka et al. previously reported a case of 39-year-old women with FT1D and coxsackie B4 virus infection [9]. The patient had 8fold increase in the plasma titer of coxsackie B4 virus neutralizing antibody after 4 weeks from FT1D diagnosis. However, to our knowledge, there are no other reports to indicate the association between FT1D and coxsackie B4 virus infection. In our case of DIHSinduced FT1D, the antibody titer of coxsackie B4 virus was increased up to 16 -fold increase. These cases suggest that abnormal immune responses to coxsackie B4 virus infection may lead to the pathogenesis of FT1D. However, it is unclear whether DIHS or susceptibility by PSL treatment induced the infection of coxsackie B4 virus in our case. Moreover, we diagnosed as DIHS 
Table 1 Virus antibody titers

\begin{tabular}{|c|c|c|c|c|c|}
\hline & First test & Second test & & First test & Second test \\
\hline CMV-IgG & 38.2 & 107 & Coxsackie A2 & 64 & 16 \\
\hline CMV-IgM & 0.79 & 0.68 & Coxsackie A3 & 8 & 16 \\
\hline EB VCA-IgG & 20 & 20 & Coxsackie A4 & $<4$ & 8 \\
\hline EB VCA IgM & 10 & $<10$ & Coxsackie A5 & 16 & 16 \\
\hline EBNA & 10 & 10 & Coxsackie A6 & $<4$ & 4 \\
\hline HHV-6 IgG & 320 & 160 & Coxsackie A7 & 8 & 16 \\
\hline HHV-6 IgM & $<4$ & $<10$ & Coxsackie A9 & $<4$ & $<4$ \\
\hline HHV-7 IgG & 40 & 40 & Coxsackie A10 & 4 & 4 \\
\hline \multirow[t]{2}{*}{ HHV-7 IgM } & $<4$ & $<10$ & Coxsackie A16 & 16 & 16 \\
\hline & & & Coxsackie B1 & $<4$ & $<4$ \\
\hline Parainfluenza B1 & 10 & $<10$ & Coxsackie B2 & $<4$ & 8 \\
\hline Parainfluenza B2 & 40 & 20 & Coxsackie B3 & $<4$ & $<4$ \\
\hline \multirow[t]{3}{*}{ Parainfluenza B3 } & 80 & 80 & Coxsackie B4 & $<4$ & 64 \\
\hline & & & Coxsackie B5 & $<4$ & $<4$ \\
\hline & & & Coxsackie B6 & $<4$ & $<4$ \\
\hline
\end{tabular}

Anti-CMV IgG and anti-CMV IgM were measured by enzyme immunoassay (EIA). Other virus antibodies were measured by fluorescence antibody technique or neutralization test. The serum samples were collected at 11 days and 54 days after the second admission.

according to the European criteria [6] although her symptoms and laboratory findings did not completely meet the Japanese criteria of DIHS [10]. In this case, anti-HHV-6 antibody titer was significantly elevated, which is an important characteristic of DIHS. Further, the immediate initiation of PSL treatment might protect becoming severe stage. Therefore, further studies and accumulation of case reports are necessary to clarify whether DIHS is involved in the incidence of FT1D with coxsackie B4 virus infection.

On the other hand, the genetic background is also important, because not all cases with coxsackie B4 virus infection or DIHS suffer FT1D. Accumulating evidence has shown the association of HLA haplotypes with susceptibility or resistance to development of FT1D $[8,11]$. Onuma et al. previously showed a higher frequency of HLA-B62 in FT1D with DIHS than that of cases without DIHS [4]. Furthermore, in their study, the frequency of
HLA-A24 tended to be high, although the association was not significant [4]. Our patient had HLA-A24, but not HLA-B62, suggesting that HLA-A24 may confer susceptibility to development of FT1D with DIHS in this case. Of interest, the present case showed HLADRB1*15:01 and DQB1*06:02, which have been reported to be resistant haplotypes [11]. It is unknown how these HLA haplotypes contribute to the pathogenesis of DIHS-induced FT1D in this case; thus, further studies are necessary.

This is the first case report suggesting that coxsackie B4 virus infection may be involved in the pathogenesis of DIHS-induced FT1D in elderly patients with HLAA24 haplotype.

\section{Disclosure}

The authors declare no conflict of interest.

\section{References}

1. Imagawa A, Hanafusa T, Miyagawa Matsuzawa Y (2000) A novel subtype of type 1 diabetes mellitus characterized by a rapid onset and an absence of diabetes-related anti- bodies. Osaka IDDM Study Group. N Engl J Med 342: 301-307.

2. Imagawa A, Hanafusa T, Uchigata Y, Kanatsuka A, 
Kawasaki E, et al. (2003) Fulminant type 1 diabetes: a nationwide survey in Japan. Diabetes Care 26: 23452352.

3. Shiohara T, Inaoka M, Kano Y (2006) Drug-induced hypersensitivity syndrome (DIHS): a reaction induced by a complex interplay among herpesviruses and antiviral and antidrug immune responses. Allergol Int 55: 1-8.

4. Onuma H, Tohyama M, Imagawa A, Hanafusa $T$, Kobayashi T, et al. (2012) High frequency of HLA B62 in fulminant type 1 diabetes with the drug-induced hypersensitivity syndrome. J Clin Endocrinol Metab 97: E2277E2281.

5. Kano Y, Tohyama M, Aihara M, Matsukura S, Watanabe $\mathrm{H}$, et al. (2015) Sequelae in 145 patients with druginduced hypersensitivity syndrome/drug reaction with eosinophilia and systemic symptoms: survey conducted by the Asian Research Committee on Severe Cutaneous Adverse Reactions (ASCAR). J Dermatol 42: 276-282.

6. Roujeau JC, Allanore Laurence, Liss Y, Mockenhaupt M (2009) Severe cutaneous adverse reactions to drugs (SCAR): Definitions, diagnostic criteria, genetic predisposition. Dermatol Sinica 27: 203-209.

7. Imagawa A, Hanafusa T, Awata T, Ikegami H, Uchigata
Y, et al. (2012) Report of the committee of the Japan diabetes society on the research of fulminant and acute-onset type1 diabetes mellitus: new diagnostic criteria of fulminant type 1 diabetes mellitus (2012). J Diabetes Investig 3: 536-539.

8. Imagawa A, Hanafusa T (2011) Fulminant type 1 diabetes - an important subtype in East Asia. Diabetes Metab Res Rev 27: 959-964.

9. Akatsuka H, Yano Y, Gabazza EC, Morser J, Sasaki R, et al. (2009) A case of fulminant type 1 diabetes with coxsackie B4 virus infection diagnosed by elevated serum levels of neutralizing antibody. Diabetes Res Clin Pract 84: e50-e52.

10. Shiohara T, Ijima M, Ikezawa Z, Hashimoto K (2007) The diagnosis of a DRESS syndrome has been sufficiently established on the basis of typical clinical feature and viral reactivations. Bri J Dermatol 156: 1083-1084.

11. Kawabata $\mathrm{Y}$, Ikegami $\mathrm{H}$, Awata $\mathrm{T}$, Imagawa $\mathrm{A}$, Maruyama T, et al. (2009) Differential association of HLA with three subtypes of type 1 diabetes: fulminant, slowly progressive and acute-onset. Diabetologia 52: 2513-2521. 